\title{
Pulse vs. Optimal Stationary Fishing: The Northern Stock of Hake
}

\author{
Jos-Mara Da-Rocha ${ }^{\mathrm{a}, \mathrm{b}}$, Mara-Jos Gutirrez ${ }^{\mathrm{c}, *}$, Lus T. Antelo ${ }^{\mathrm{d}}$ \\ ${ }^{a}$ Universitat Autònoma de Barcelona. Campus de la UAB, 08193 Bellaterra (Cerdanyola del Valls), Spain \\ ${ }^{b}$ RGEA-Universidade de Vigo, Facultad CC. Econmicas, Campus Universitario Lagoas-Marcosende, C.P. 36200 \\ Vigo, Spain \\ ${ }^{c}$ FAEII and MacLab - University of the Basque Country, Avda. Lehendakari Aguirre, 83, 48015 Bilbao, Spain. \\ ${ }^{d}$ Process Engineering Group. Instituto de Investigaciones Marinas (IIM) CSIC. C/ Eduardo Cabello, 6. 36208
} Vigo, Spain.

\begin{abstract}
Pulse fishing may be a global optimal strategy in multicohort fisheries. In this article we compare pulse fishing solutions obtained by using global numerical methods with the analytical stationary optimal solution. This allows us to quantify the potential benefits associated with the use of periodic fishing in the Northern Stock of hake. Results show first that management plans based exclusively on traditional reference targets such as $F_{m s y}$ may drive economic results for fisheries far away from the optimal; second, that global optimal solutions would imply the cyclical closure of fisheries for some periods; and third, that second best stationary policies with stable employment only reduce the optimal present value of discounted profit by $2 \%$.

Keywords:

optimal fishery management, optimization in age-structured models, pulse fishing
\end{abstract}

\section{Introduction}

Ever since Beverton and Holt (1957) target reference points have been one of the main tools used by fishery managers to make decisions about future catch options. Among the classical target reference points $F_{m s y}$ (the fishing mortality rate) stands out. If applied constantly it results in the maximum sustainable yield, $M S Y$ (Caddy and Mahon, 1995).

There are two major shortcomings in this classical reference point approach. First, $F_{m s y}$ is time independent and fishery management strategies are evaluated using time-dependent indicators, usually the net present values of profits. Second, $F_{m s y}$ is a stationary concept and optimal harvesting in a multi-cohort model may take the form of periodic fishing (Clark, 1976; Spulber, 1983; McCallum, 1988; Tahvonen, 2009).

\footnotetext{
${ }^{*}$ Corresponding author. Phone: 34-94-6013786, Fax: 34-94-6017123, e-mail: mariajose.gutierrez@ehu.es

Email addresses: JoseMaria.DaRocha@uab.cat (Jos-Mara Da-Rocha), mariajose.gutierrez@ehu.es (Mara-Jos Gutirrez), Itaboada@iim.csic.es (Lus T. Antelo)
} 
In order to overcome these drawbacks, numerical methods have been implemented to find the optimal fishing mortality trajectory that maximizes the net present profits of a fishery using the Beverton-Holt multi-cohort models (Hannesson, 1975; Horwood, 1987; Björndal et al., 2004a, 2004b and 2006). In all these cases, the optimal solution of the problem is non stationary but consists of pulse fishing, i.e. periodic cycles of fishing followed by fallow periods for stock to recover. This means that periodic fishing leads to higher profits than those obtained from fishing at a constant stationary rate. It is worth mentioning that pulse fishing may be optimal in this context because it mitigates the consequences of imperfect gear selection.

Pulse fishing has some advantages in live product fisheries (Graham, 2001) and it has been applied for many years, under spatial rotation, in location-specific areas with marine invertebrates and sedentary reef fishes (Caddy, 1993; Botsford et al., 1993; Hart, 2003; Hart and Rago, 2006; Cinner et al., 2006). Nevertheless, fishery agencies do not consider periodic fishing as a feasible management tool, mainly because if rotation is not possible its application may imply high financial and social costs. If rotation is not possible, periodic fishing means the cyclical closure of fisheries for some periods with no alternative use of the fleet. As a result, most fishery agencies consider that fishery management must be stationary.

Optimal stationary solutions have recently been assessed for different fisheries (Dichmont et al., 2010; Grafton et al., 2006, 2007, 2010; Kompas et al., 2010; Kulmala et al., 2008; Da Rocha et al., 2010; Da Rocha and Gutiérrez, 2011). In a seminal paper Grafton et al. (2007) analyze the biomass associated with yield maximization and discounted profit maximization for Western and Central Pacific big eye tuna and yellowfin tuna, the Australian northern prawn fishery and the Australian orange roughy fishery. They find that stationary fishing mortality maximizing net present profit is a win-win strategy compared to the usual reference point policy, achieving higher profits and safer biomass. As a result of this study, the Australian federal government started to manage 26 species based on profit maximization as from the beginning of 2008 (Black, 2007).

However, we know that the Beverton-Holt multi-cohort model used to assess the stock is not globally concave, so it is possible that constrained stationary solutions may be locally but not globally optimal. If this is the case, what is the relative advantage of pulse fishing with respect to optimal stationary fishing mortalities in a Beverton-Holt multi-cohort model? In this paper we quantify the potential benefits associated with the use of periodic fishing in the Northern Stock of hake. In particular, we compare the solutions obtained by using global numerical methods with the analytical stationary optimal solution. This allows us to measure the potential benefits of periodic fishing relative to the optimal institutional constrained solution. We find that when periodic fishing is compared to optimal stationary solutions rather than to time-independent classical reference 
thortality rates and initial recruitment,

$$
N_{t}^{a}=e^{-z_{t-1}^{a-1}\left(F_{t-1}\right)} N_{t-1}^{a-1}=e^{-z_{t-1}^{a-1}\left(F_{t-1}\right)} e^{-z_{t-2}^{a-2}\left(F_{t-2}\right)} N_{t-2}^{a-2}=\ldots=\Pi_{i=1}^{a-1} e^{-z_{t-i}^{a-i}\left(F_{t-i}\right)} N_{t-(a-1)}^{1} .
$$

Therefore $N_{t}^{a}$ can be expressed as

$$
N_{t}^{a}=\phi_{t}^{a} N_{t-(a-1)}^{1}, \quad \text { for } a=1, \ldots A,
$$

where

$$
\phi_{t}^{a}=\phi\left(F_{t-1}, F_{t-2}, \ldots F_{t-(a-1)}\right)= \begin{cases}1 & \text { for } a=1, \\ \prod_{i=1}^{a-1} e^{-z_{t-i}^{a-i}\left(F_{t-i}\right)} & \text { for } a=2, \ldots . . A,\end{cases}
$$


$t-(a-1)$ reaching age $a>1$ for a given fishing mortality path $\left\{F_{t-1}, F_{t-2}, \ldots F_{t-(a-1)}\right\}$.

The size of a new cohort (recruitment), $N_{t+1}^{1}$, depends on the spawning stock biomass in the previous year, $S S B_{t}$,

$$
N_{t+1}^{1}=\Psi\left(S S B_{t}\right)
$$

where $\Psi$ denotes the stock/recruits (S-R) relationship. Moreover, the spawning stock biomass, $S S B$, is a function of the stock weight distribution, $\omega$, and the maturity fraction, $\mu$, of each age,

$$
S S B_{t}=\sum_{a=1}^{A} \mu^{a} \omega^{a} N_{t}^{a} .
$$

Let $D_{t}^{a}$ and $C_{t}^{a}$ denote the number of fish that die from natural causes and from fishing (catches), respectively. Then the dynamics of the cohort can be expressed as

$$
N_{t}^{a}-N_{t+1}^{a+1}=D_{t}^{a}+C_{t}^{a} .
$$

Taking into account equation (1) and the definitions of natural and fishing mortality, $D_{t}^{a}$ and $C_{t}^{a}$ can be expressed as

$$
\begin{aligned}
& D_{t}^{a}=\frac{m^{a}}{z_{t}^{a}}\left(N_{t}^{a}-N_{t+1}^{a+1}\right)=\frac{m^{a}}{z_{t}^{a}}\left(1-e^{-z_{t}^{a}}\right) N_{t}^{a}, \\
& C_{t}^{a}=\frac{F_{t}^{a}}{z_{t}^{a}}\left(N_{t}^{a}-N_{t+1}^{a+1}\right)=\frac{F_{t}^{a}}{z_{t}^{a}}\left(1-e^{-z_{t}^{a}}\right) N_{t}^{a} .
\end{aligned}
$$

This last equation is known as the Baranov catch equation (Baranov, 1918).

\section{Optimal Management}

The profits of the fishery for any period $t$ are given by the difference between revenues and fishing cost. That is

$$
\pi_{t}=\sum_{a=1}^{A} p r^{a} C_{t}^{a}\left(F_{t}\right)-T C\left(F_{t}\right),
$$

where $p r^{a}$ is the selling price for a unit of fish of age $a$ and $T C$ represents the total fishing cost which depend on the fishing rate. For the sake of simplicity it is assumed that prices are assumed to be constant over time and total cost is a convex function. In the Discussion in Section 5 we discuss the implications of these assumptions based on the sensitivity analysis carried out.

Note that $\pi_{t}$ can be interpreted in several ways from the economic point of view (Da Rocha et al., 2011). For instance, $\pi_{t}$ represents the yield of the fishery in value if the cost is zero, and in weight if the price is one. 
where $y^{a}\left(F_{t}\right)=\omega^{a} \frac{F_{t}}{p^{a} F_{t}+m^{a}}\left(1-e^{-p^{a} F_{t}-m^{a}}\right)$.

The appendix shows how to find the first order conditions that solve this problem. Formally, the optimal paths can be characterized by the following set of dynamic equations

$$
\begin{gathered}
\sum_{a=1}^{A} p r^{a} \frac{\partial y^{a}\left(F_{t}\right)}{\partial F_{t}} N_{t}^{a}-\frac{1}{N_{t}^{a}} \frac{\partial T C_{t}}{\partial F_{t}}=\sum_{a=1}^{A-1} p^{a}\left\{\sum_{j=1}^{A-a} \beta^{j}\left[p r^{a} y^{a+j}\left(F_{t+j}\right)+\left(\Psi_{t+j}^{\prime} \lambda_{t+j}+\theta_{t+j}\right) \mu^{a+j} \omega^{a+j}\right] N_{t+j}^{a+j}\right\} \\
\sum_{a=1}^{A} \beta^{a} p r^{a} y^{a}\left(F_{t+1+a}\right) \phi_{t+1+a}^{a}=\lambda_{t+1}-\sum_{a=1}^{A} \beta^{a}\left(\Psi_{t+1+a}^{\prime} \lambda_{t+1+a}+\theta_{t+1+a}\right) \mu^{a} \omega^{a} \phi_{t+1+a}^{a} \\
N_{t+1}^{a+1}=e^{-z^{a}\left(F_{t}\right)} N_{t}^{a}, \quad \forall t \quad \forall a=1, \ldots A-1 \\
N_{t+2}^{1}=\Psi\left(\sum_{a=1}^{A} \mu^{a} \omega^{a} N_{t+1}^{a}\right), \quad \forall t \\
\theta_{t+1}\left[\sum_{a=1}^{A} \mu^{a} \omega^{a} N_{t+1}^{a}-S S B_{p a}\right]=0,
\end{gathered}
$$


where $\lambda_{t}$ and $\theta_{t}$ are the Lagrange multipliers associated with the first and second restrictions of the maximization problem (7), respectively.

Condition $(8)$ shows how the mortality rate, $F_{t}$, is selected. The insight is the following. On the optimal path, an increase in current mortality rate leads to an increase in current fishery profits (left-hand side) that is offset by a decrease in future profits derived from reductions in future stock (right-hand side). In particular, the left-hand side represents the effects of changes in fishing mortality on the current profit of the fishery. However, the right-hand side shows the effect on the future size of the living cohorts, $t+1$ to $t+A-1$ (first sum) and on future stock recruitments from periods $t+2$ to $t+A$ (second sum). This can also be visualized by looking at age structure in Table 1. The left-hand side represents the effects of $F_{t}$ on the structure of the fishery in period $t$ (column $t$ ). The first sum on the right-hand side shows the effects of $F_{t}$ on the structure of future size of the living cohorts (lower triangle matrix) and the second sum illustrates the effects of $F_{t}$ on future stock recruitments (row $a=1$ ). Note that $\beta$ affects the future net present value (right side). Note that making $\beta=1$ implies caring about future changes as much as if they occurred in the current year. By contrast, considering $\beta=0$ implies not caring about the future at all.

[Insert Table 1]

Equation (9) indicates that the optimal path recognizes that an increase in the stock recruitment, $N_{t+2}^{1}$, has two effects. On the one hand, the abundance in periods $t+2$ to $t+2+A-1$ increases, which leads to an increase in catches (left-hand side). On the other hand, the $S S B$ for periods $t+3$ to $t+3+A-1$ also increases, (right-hand side).

Equations (10) and (11) show the dynamics of the population cohorts. Finally, equation (12) indicates whether $S S B$ is below the precautionary level, $S S B_{p a}$. The Lagrange multiplier $\theta_{t}$ shows the effects on mortality when the precautionary principle is not binding. If at a period $t$ the $S S B$ is below the precautionary level, $S S B_{p a}$, then $\theta_{t}$ indicates how much the fishing mortality rate should be modified between periods $t-A$ and $t-1$.

\subsection{Optimal Stationary Solution}

The optimal trajectories derived from maximization problem (7) are the optimal paths for $\left\{F_{t}\right\}_{t=1}^{\infty},\left\{\lambda_{t}\right\}_{t=2}^{\infty}$, and $\left\{N_{t+2}^{a}\right\}_{t=1}^{\infty}$ which satisfy the infinite set of equations that characterizes the first order conditions (8) to (12). This section focuses on solutions that solve the manager maximization problem leading the fishery to a stationary situation. Our strategy for finding these optimal stationary trajectories follows two steps. First, we algebraically characterizes the stationary solution, i.e. the solution that determines a unique value for the long-term fishing rate which, if 

to the stationary solution is found using numerical methods.

Assume that the precautionary restriction is not binding, $\theta_{t}=0$. In this context, a stationary solution is defined as an optimal solution characterized by a vector $\left(F_{s s}, N_{s s}^{1}, N_{s s}^{2}, \ldots N_{s s}^{A}, \lambda_{s s}\right)$ such that for any future period $t$

$$
\begin{array}{ll}
F_{s s}=F_{t}=F_{t+1}, & \\
N_{s s}^{a}=N_{t}^{a}=N_{t+1}^{a}, & \forall a=1, . ., A, \\
\lambda_{s s}=\lambda_{t}=\beta^{j} \lambda_{t+j}, & \forall j=1, . ., A+1 .
\end{array}
$$

The first order conditions (8)-(11) valued at the stationary solution can be reduced to the following 3-equation system,

$$
\begin{aligned}
\sum_{a=1}^{A} p r^{a} \frac{\partial y^{a}\left(F_{s s}\right)}{\partial F_{s s}} \phi_{s s}^{a} N_{s s}^{1}-\frac{\partial T C}{\partial F_{s s}} & =\sum_{a=1}^{A-1} p^{a}\left\{\sum_{j=1}^{A-a}\left[\beta^{j} p r^{a} y^{a+j}\left(F_{s s}\right)+\Psi^{\prime} \lambda_{s s} \mu^{a+j} \omega^{a+j}\right] \phi_{s s}^{a+j} N_{s s}^{1}\right\} \\
\sum_{a=1}^{A} \beta^{1+a} p r^{a} y^{a}\left(F_{s s}\right) \phi_{s s}^{a} & =\lambda_{s s}\left[1-\Psi^{\prime} \sum_{a=1}^{A} \mu^{a} \omega^{a} \phi_{s s}^{a}\right] \\
N_{s s}^{1} & =\Psi\left(\sum_{a=1}^{A} \mu^{a} \omega^{a} \phi_{s s}^{a} N_{s s}^{1}\right)
\end{aligned}
$$

where $\phi_{s s}^{a}$ is the the survival function valued in the stationary solution, $F_{s s}$.

Equations (13)-(15) can be solved for $\left(F_{s s}, N_{s s}^{1}, \lambda_{s s}\right)$. Once $N_{s s}^{1}$ is known the cohort size of any age can be calculated using the survival function valued in the stationary solution, i.e. $N_{s s}^{a}=$ $\phi^{a}\left(F_{s s}\right) N_{s s}^{1}$.

It is worth mentioning that equations (13)-(15) allow the stationary reference point that maximizes the net present value of the fishery profits to be calculated. This reference point characterizes the optimal size of the resource and the age structure of the population. Equation (13) evaluates the effect of the stationary fishery rate on the sum of the net present value of the current and future profits. Equation (14) determines the optimal number of fish in the stationary solution. Finally, equation (15) shows the relationship between age structure and stock. This stationary solution is a generalization, in infinite time, to the classical maximum economic yield (MEY). If the discount factor $\beta$ is one then the stationary fishing rate coincides with $F_{m e y}$.

To make the computation of the optimal trajectories that drives the fishery from the initial conditions to the stationary solution described above tractable, we assume that convergence is 
reached in a finite number of periods, $T$. In other words we truncate the first order conditions using that $F_{T}=F_{s s}, N_{T+2}^{1}=N_{s s}^{1}$, and $\lambda_{T+1}=\lambda_{s s}$. Taking this into account, the model is solved by choosing $F_{1}, F_{1}, F_{2}, \ldots ., F_{T}=F_{s s}$ such that the system of equations implied by the first order condition (8)-(9) is satisfied. This system of $(T-1)$ nonlinear equations with $(T-1)$ unknowns can be solved relatively quickly using standard numerical methods following the algorithm below:

1. Collect all the exogenous parameters that describe biological and economic characteristics of the fishery. This includes the biological parameters $\left(\omega^{j}, \mu^{j}, p^{j}, m^{j}\right)$, the initial population distribution $\left(N_{0}^{j}\right)$, the precautionary limit reference point $\left(S S B_{p a}^{j}\right)$, the economic parameters $\left(p r^{j}, T C\right)$, and the discount factor used to calculate variables in present terms, $\beta$.

2. Using outside information, select the $S-R$ relationship to be used. With this relationship, it is possible to find the recruitment for any fishing rate from optimal condition (15). Some examples:

- If the $S-R$ relationship is defined as the Shepherd relationship ${ }^{1}$ (1982),

$$
N_{t}^{1}=\frac{\alpha S S B_{t}}{1+\left(\frac{S S B_{t}}{K}\right)^{b}},
$$

then recruitment is determined by

$$
N_{t}^{1}=K \frac{\left(\alpha \sum_{a=1}^{A} \mu^{a} \omega^{a} \phi_{t}^{a}-1\right)^{1 / b}}{\sum_{a=1}^{A} \mu^{a} \omega^{a} \phi_{t}^{a}} .
$$

So, $\alpha, K$ and $b$ have to be reported.

- If the $S-R$ relationship is not well defined then recruitment may be considered as a fixed variable that does not depend on fishing rate, that is $N_{t}^{1}=\overline{N^{1}}$.

3. Assume that the fishery is above the precautionary level. That is $S S B_{t}>S S B_{p a} \forall t$, and therefore $\theta_{t}=0, t=2, . ., T$. Compute the stationary solution, $\left(F_{s s}, N_{s s}^{1}, \lambda_{s s}\right)$ implied by (13)-(15).

4. Guess a trajectory for the fishing mortality rate path, $\left\{F_{t}\right\}_{t=1}^{T-1}$, and assume that in period $T$ the steady state has been reached, i.e. $F_{T}=\ldots=F_{T+A+1}=F_{s s}$.

5. Project the future age cohort structure for periods $1, \ldots, T+A+1,\left\{N_{t}^{a}\right\}_{t=1}^{T+A+1}$ using the initial age structure, $N_{0}^{a}$, and the S-R relationship. To do this, use the cohort dynamic population (1), and the recruitment relationship, (3) and (4).

\footnotetext{
${ }^{1}$ Parameter $\alpha$ is the maximum recruitment attainable when the $S S B$ is very low, $K>0$ is a threshold of $S S B$ below which the likelihood of population collapse is increased and $b>0$ measures the power of the density-dependent effects.
} 
6. Compute $\Psi_{t}^{\prime}=\frac{d N_{t}^{1}}{d S S B_{t}}$ using the recruitment relationship, (3) and (4), associated with $\left\{N_{t}^{a}\right\}_{t=1}^{T+A+1}$.

7. Using $\lambda_{s s}$ compute $\lambda_{T}$ from equation (9) valued at $t=T-1$,

$$
\lambda_{T}=\sum_{a=1}^{A} \beta^{a} p r^{a} y^{a}\left(F_{s s}\right) \phi_{s s}^{a}+\sum_{a=1}^{A} \Psi_{T+a}^{\prime} \lambda_{s s} \mu^{a} \omega^{a} \phi_{s s}^{a} .
$$

Note that $\Psi_{T+a}^{\prime}$ is a function of $N_{T+a}^{1}$ which depends on the guess $\left\{F_{t}\right\}_{t=1}^{T+a-2}$.

8. Given $\lambda_{T}$, compute $\left\{\lambda_{t+1}\right\}_{t=1}^{T-1}$ backwards recursively using equation (9).

9. Using the values of $\left\{\lambda_{t+1}\right\}_{t=1}^{T-1}$, the guess of $\left\{F_{t}\right\}_{t=1}^{T-1}$ and the cohort projections $\left\{N_{t}^{a}\right\}_{t=1}^{T+A+1}$, it is now possible to compute the distance from the first order condition (8). Formally the following is calculated: $\forall t=1, \ldots . T$,

$$
\begin{aligned}
f_{t} & =\sum_{a=1}^{A} p r^{a} \frac{\partial y^{a}\left(F_{t}\right)}{\partial F_{t}} N_{t}^{a}-\frac{\partial T C_{t}}{\partial F_{t}} \\
& -\sum_{a=1}^{A-1} p^{a}\left\{\sum_{j=1}^{A-a} \beta^{j}\left[p r^{a} y^{a+j}\left(F_{t+j}\right)+\left(\Psi_{t+j}^{\prime} \lambda_{t+j}+\theta_{t+j}\right) \mu^{a+j} \omega^{a+j}\right] N_{t+j}^{a+j}\right\} .
\end{aligned}
$$

Using an appropriate algorithm, make another guess at the mortality rate path.

10. Repeat the procedure for step 4 to 9 until $f_{t}$ is low enough.

11. Finally check that $\left\{\sum_{a=1}^{A} \mu^{a} \omega^{a} N_{t}^{a}\right\}_{t=1}^{T}>S S B_{p a}$. If the restriction is not satisfied, guess a new set of positives values for ${ }^{2}\left\{\theta_{t}\right\}_{t=2}^{T}$.

\subsection{Global Optimal Solutions: Pulse Fishing}

It is well known that the Beverton-Holt multi-cohort models used to assess the stock are not globally concave. Therefore the constrained stationary solution described in Section 3.1 may be a local rather than a global optimum (Tahvonen 2009).

In order to seek the global solution, we start by rewriting the original dynamic optimization problem of infinite dimension, (7), in continuous time. Let $n(a, t)$ be the number of fish of age $a$ at time $t$. In age structured models, the conservation law is described by the following McKendrick-von Foerster partial differential equation (Von Forester, 1959; McKendrick, 1926)

$$
\frac{\partial n(a, t)}{\partial t}=-\frac{\partial n(a, t)}{\partial a}-[m(a)+p(a) F(t)] n(a, t) .
$$

Equation (16) shows that the rate of change of the number of fish in a given age interval, $\frac{\partial n(a, t)}{\partial t}$, is equal to the net rate of departure less the rate of deaths. Given all fish age, the net rate of

\footnotetext{
${ }^{2}$ In long-run management plans, the stock is usually far from $S S B_{p a}$. So for those cases the best initial guess is $\theta_{t}=0$.
} 

period, the number of fish of age zero is given by the Stock Recruitment relationship

$$
n(0, t)=\Psi\left(\int_{0}^{A} \omega(a) \mu(a) n(a, t) d a\right) .
$$

where, $\int_{0}^{A} \omega(a) \mu(a) n(a, t) d a$ is the SSB. Finally we also assume that fish die at age $A$, i.e.

$$
n(A, t)=0
$$

In continuous time, catches at age $a$ are equal to $p(a) F(t) n(a, t)$ and profits from catches of age $a$ are $\operatorname{pr}(a) \omega(a) p(a) F(t) n(a, t)-C(F(t))$. Therefore, the objective function is equal to

$$
\int_{0}^{\infty}\left[\left(\int_{0}^{A} \operatorname{pr}(a) \omega(a) p(a) n(a, t) d a\right) F(t)-C(F(t))\right] e^{-r t} d t
$$

where $r$ is the instantaneous interest rate, which is related to the discount factor in such a way that $\beta=(1+r)^{-1}$. Therefore, the problem in continuous time is given by

$$
\begin{aligned}
& \max _{F(t)} \quad J= \int_{0}^{\infty}\left[\left(\int_{0}^{A} \operatorname{pr}(a) \omega(a) p(a) n(a, t) d a\right) F(t)-C(F(t))\right] e^{-r t} d t, \\
& \text { s.t. }\left\{\begin{array}{l}
\frac{\partial n(a, t)}{\partial t}=-\frac{\partial n(a, t)}{\partial a}-[m(a)+p(a) F(t)] n(a, t) . \quad \forall t, a \\
n(0, t)=\Psi(S S B(t)) \forall t, \\
S S B(t)=\int_{0}^{\infty} \mu(a) \omega(a) n(a, t) d a . \forall t \\
S S B(t) \geq B_{p a} . \forall t \\
n(A, t)=0 \forall t, \\
n(a, 0) \quad \text { given, } \forall a
\end{array}\right.
\end{aligned}
$$

Seeking to find the global solution, we transform the original dynamic optimization problem of infinite dimension, (17), into a low dimension non-linear optimization problem. This transformation is carried out using the control vector parameterization approach (Vassiliadis, 1993; Vassiliadis et al., 1994) which consists of: First, dividing the considered time horizon into $\rho$ constant (equidistant 
or not) or variable time intervals. Second, the controls are approximated in each interval by using different base functions, generally low order polynomials (zero order - steps, and order one - ramps, as shown in Figure 1). The coefficients of the polynomials considered constitute a vector that also includes the lengths of the intervals. For the case of one control variable, the approximation of this variable is given by

$$
u(t)=F_{i} \quad \forall i \quad t_{i-1} \leq t<t_{i-1}+q_{i} .
$$

So the vector of decision variables is formed by both the value of the steps and the time interval lengths: $\left[F_{1}, \ldots, F_{\rho}, q_{1}, \ldots, q_{\rho-1}\right] \in R^{2 \rho-1}$.

[Insert Figure 1]

This parametrization transforms the original dynamic optimization problem of infinite dimension into a non-linear optimization problem (NLP) of finite dimension where the time invariant parameters and control parametrization coefficients are the new vector of decision variables. As a consequence, this new problem can be solved by employing different optimization algorithms considering that in each internal iteration the process dynamics need to be integrated in order to evaluate both the objective function and the constraints.

In our application, to transform of the infinite dynamic optimization problem (17) into the NLP of finite dimension, the time horizon is divided into $\rho=80$ constant time intervals and the controls in each interval are approximated using ramps.

Once the NLP of finite dimension is set, stochastic optimization algorithms are used to solve it. In particular two global stochastic optimization algorithms plus one hybrid strategy are considered to solve the transformed optimization problem. The main characteristics of each method are described briefly below:

- DE: Differential Evolution. This is a metaheuristics algorithm for global optimization of nonlinear and (possibly) non-differentiable continuous functions presented by Storn and Price (1997). It is a population-based method which, starting with a randomly generated population, computes new candidate solutions by calculating differences between population members. It handles stochastic variables by means of a direct search method which outperforms other popular global optimization algorithms, and is widely used by the evolutionary computation community.

- eSS-SSm: Enhanced Scatter Search. As presented in Egea et al. (2009), Scatter Search is a population-based metaheuristic method which combines a global phase with an intensification method (i.e. a local search). This methodology is very flexible, since each of its elements 
can be implemented in a variety of ways and degrees of sophistication. A basic design for implementing scatter-search is given in the well-known "five-method template" (Laguna and Martí, 2003): (1) A Diversification Generation Method to generate a collection of diverse trial solutions. (2) An Improvement Method to transform a trial solution into one or more enhanced trial solutions. (3) A Reference Set Update Method to build and maintain a reference set consisting of the $b$ "best" solutions found, where the value of $b$ is typically small compared to the population size of other evolutionary algorithms. Solutions gain membership to the reference set according to their quality or their diversity. (4) A Subset Generation Method to operate on the reference set, to produce several subsets of its solutions as a basis for creating combined solutions. (5) A Solution Combination Method to transform a given subset of solutions produced by the Subset Generation Method into one or more combined solution vectors.

eSS-SSm is an advanced scatter search method developed by the IIM-CSIC Process Engineering Group for chemical and bioprocess optimization problems that provides excellent results.

- Hybrid strategies: The key concept of hybrid methods is synergy. Hybrid methods seek to exploit the best properties of different methodologies. They combine global stochastic and local optimization algorithms. The global ones cover the whole search space to find the global optimum, but they are slow in finding the exact location of that global solution. A promising strategy consists of obtaining a good initial guess with one of these global methods and then fine tuning employing local optimization. These strategies take advantage of both the robustness of stochastic solvers and the efficiency of local methods when started in the optimum neighborhoods. In this article, the hybrid strategy considered is $S S m+D H C$.

The DHC algorithm (Dynamic Hill Climbing; De la Maza and Yuret, 1994) draws on ideas from genetic algorithms, hill climbing and conjugate gradient methods. It is a direct search algorithm which explores every dimension of the search space using dynamic steps. It is formed by inner and outer loops. The inner loop contains a very efficient technique for locating local optima while the outer loop ensures that the entire search space has been explored. In this study, only the local phase of the algorithm has been used.

To select the algorithm that leads to the best results, it is necessary to perform an efficiency analysis. To that end convergence curves, which show the evolution of the best value obtained by each solver over the CPU time are constructed. With these representations, both robustness 
(the capability of the solver to attain consistently good final solutions) and efficiency (the speed of convergence to the final solution) can be evaluated, allowing the user to select an appropriate algorithm to solve a given optimization problem.

\section{The Northern Stock of Hake}

In order to compare the optimal stationary and pulse fishing solutions, we apply the methods described above to the Northern Stock of Hake (NSH). The NSH is a fishery managed with the advice of the International Council for the Exploitation of the Sea (ICES) and includes all fisheries in subareas VII and VIII and also some fisheries in Subareas IV and VI (see Figure 2). Hake (merluccius merluccius) is caught throughout the year, though the peak landings are made in the spring-summer months. It spawns from March to July at depths of 120-160 m., mainly to the south and west of Ireland and moves to shallower water by September. The two major nursery areas are the Bay of Biscay and off southern Ireland. As they become mature, the fish disperse to offshore regions of the Bay of Biscay and Celtic Sea. Male hake mature at 3-4 years old $(27-35 \mathrm{~cm})$ and females at 5-7 years old $(50-70 \mathrm{~cm})$.

[Insert Figure 2]

Hake has been the main species supporting trawling fleets off the Atlantic coasts of France and Spain since the 1930s. The three main gear types used by vessels fishing for hake as a target species are lines (Spain), fixed-nets and other trawls (all countries). Landings in 2008 were 47, 800 tonnes, below the regulated TAC of 54,000 tonnes. Spain accounts for 53\% of total captures. France for $30 \%$ of the total, the UK for $7 \%$, Denmark for 3\%, Ireland for $3 \%$ and other countries (Norway, Belgium, Netherlands, Germany, and Sweden) for smaller amounts (ICES 2009). Tables 2 and 3 display the main characteristics of the Spanish and French fleets according to the European Data Collection Regulation, respectively.

[Insert Table 2]

[Insert Table 3]

After the collapse of spawning $S S B$ in the 1990s, an emergency plan was implemented for the NSH in 2001 and 2002 (EC 1162/2001, EC 2602/2001 and EC 494/2002). After this emergency plan, a recovery plan was implemented in 2004 (EC 811/2004). Its aim was to achieve an $S S B$ of 140,000 tonnes $\left(B_{p a}\right)$ by limiting fishing mortality to 0.25 and by allowing a maximum change in harvest in consecutive years of $15 \%$. The recovery plan was to be replaced by a management plan 


\footnotetext{
${ }^{3}$ To calculate prices as a function of ages we use data on 2007 daily sales for the Galician trawl, gill net and long line fleets.
} 
In our numerical simulations we assume that the cost of effort is proportional to the mortality rate, $T C=c F$, where $c=T C / F$ represents the average and marginal costs. Once the total costs are known, $c$ is calibrated as this amount divided by the current mortality rate, $F=0.25$.

To calibrate total costs, we start by determining the running costs per day. First we calculate fuel costs, other costs, depreciation and interest divided by the days at sea of each segment (see Table 6). Second, the average costs weighted by the sea days for each segment are calculated (last column in Table 6). Third, the fuel costs are adjusted taking into account the increases in fuel prices in 2007. Since fuel prices rose from 0.346 Euros in late 2006 to 0.52 in early 2008 , fuel costs have been multiplied by 1.5. These calculations imply a cost of the fishery of 1,919.14 Euros per day. Since the hake dependency of the fleet is 0.28 , the costs per day imputed to hake are 542.50 Euros per day.

\section{[Insert Table 6]}

We assume that 543.17 Euros per day and 135, 635 days at sea are good proxies for the marginal cost and total effort, respectively, so the total cost can be considered as $C(F)=543.17 \times 135,635=$ 73.57 millions Euros.

We define three different scenarios for the problem proposed:

- Scenario 1: The smooth trajectory that drives the fishery from the initial conditions to $F_{m s y}$ using a constant annual reduction in fishing mortality of $15 \%{ }^{4}$

- Scenario 2: The trajectory that drives the fishery smoothly from the initial conditions to the optimal stationary solution.

- Scenario 3: The trajectory that drives the fishery from the initial conditions to the global optimal solution.

Scenario 1 is simulated calculating $F_{m s y}$ as the fishing rate that maximizes the stationary yield. In Scenario 2 the optimal stationary trajectory is obtained using the algorithm described in Section 3.1 .

Scenario 1 results in $F_{m s y}=0.172$. In Scenario 2 the optimal stationary trajectory is obtained using the algorithm described in Section 3.1. As a result $F_{s s}=0.119$ is obtained for the NSH.

In relation to Scenario 3, the three global methods described in Section 3.2 were applied to the NSH considering a time horizon of 80 periods for the transformed problem. Several runs

\footnotetext{
${ }^{4}$ This scenario is similar to the management strategy proposed by the Expert Working Group in the Long-Term Plan for this fishery (STECF/SGBRE-07-03).
} 
$(n=5)$ were performed on an Intel Core2 Quad 2.40 GHz computer for the algorithms considered to solve the NLP problem associated with the maximization problem (3) to attain an average function $J$. The maximum CPUtime was set at 8 hours. An efficiency analysis of the results for the three global methods led to the selection of the hybrid strategy. This method converges to high quality solutions faster than the other global stochastic optimization algorithms considered. With this hybrid strategy, the global optimal solution for the NSH consists of fishing every four years applying a fishing rate of $F_{\text {periodic }}=0.489$ in the harvesting years and three consecutive fallow years.

\subsection{Results}

Table 7 summarizes the quantitative results for the three trajectories. The long-run values for each scenario are shown for $F, S S B$, yield and the net present value of profits. The net present value of the profits associated with each trajectory is calculated using $\beta=0.95$. Figure 3 shows the changes over time in $F, S S B$ and the yield under the three scenarios.

[Insert Table 7]

[Insert Figure 3]

Optimal stationary reference points that maximize profits imply lower long run fishing mortality and higher long-run SSB than strategies based on $F_{m s y}$. While $F_{m s y}=0.172$, the optimal stationary fishing mortality is $F_{s s}=0.119$. As a result, while $S S B_{m s y}$ is $198,070 \mathrm{kT}$, the SSB associated with the optimal stationary reference points that maximizes profits is equal to $254,140 \mathrm{kT}$.

Moreover, the optimal stationary trajectory implies higher net present profit than the $F_{m s y}$ trajectory. The optimal stationary trajectory represents $19 \%$ more present value of profits than the $F_{m s y}$ trajectory. This result is in line with that of Grafton et al. (2007). Maximizing profits is a win-win strategy.

Nevertheless the stationary solution is not the global optimum. The global optimal solution for the NSH is periodic, and consists of fishing every four years applying a fishing rate of $F_{\text {periodic }}=$ 0.489 in the harvesting years and three consecutive fallow years.

Although the global optimum is periodic fishing, in terms of present value of profits the pulse fishing solution represents only $2 \%$ more present value of profits than trajectories based on stationary solutions.

Moreover, the global optimum implies $S S B$ cycles which are not in the rank of the historical data. Notice that even for the optimal pulse trajectory the $S S B$ levels implied are safe over time 
(that is, higher than 140,000 kT). However,the four-year period predicted by the model, 354,760 $\mathrm{kT}$, is higher than the maximum $S S B$ recorded in the historic data.

When costs are not considered the potential benefit from a periodic trajectory is lower (See Table 8). In terms of present value of profits the pulse fishing solution represents around $1 \%$ more present value of profits than trajectories based on stationary solutions. Moreover, $F_{m s y}$ is close to the optimal stationary fishing mortality. This implies similar present value of profits associated with both smooth trajectories.

[Insert Table 8]

\section{Discussion and policy recommendation}

In this study we show that the advantages of pulse fishing are lower when compared to stationary trajectories than to reference points. The results of numerical simulations show that pulse fishing entails far lower benefits than indicated previously in the relevant literature.

These results were obtained using constant prices and linear costs in fishing mortality. These assumptions are very similar to those in Hanneson (1975). However, the advantages of pulse fishing are closely related to them.

Is it reasonable to assume that hake prices will remain constant over time? When it is possible to alternate between different stocks of hake and/or to freeze catches from one year for the next, it can be assumed that pulse fishing solutions can be implemented while maintaining a constant supply over time. In that case, the constant price assumption seems reasonable.

But the NSH is a fresh fishery. Vessels may be at sea for 10-15 days, and the prices of their landings - which depend on size - are higher than those of frozen hake imported from other fisheries (Namibia, Argentina).

Price changes could be introduced into the model in two ways. If it is assumed that there are no differences in the price per $\mathrm{kg}$ for fish of different sizes, it suffices to assume that prices are isoelastic functions of quantities. In that case, revenues can be written as

$$
\left[\sum_{a=1}^{A} \bar{p} y^{a}\left(F_{t}\right) N_{t}^{a}\right]^{(1-\epsilon)} .
$$

This assumption is used to assess the economic impact of management plans. The value considered for this assessment is $\epsilon=0.2$.

If it is assumed that the price per $\mathrm{kg}$ varies for fish of different sizes, price elasticities can be introduced via age in a way very similar to the above case. If $p r^{a}=\bar{p}^{a} Y^{a-\epsilon}$, then revenues can be 
written as

$$
\sum_{a=1}^{A}\left[\bar{p}^{a} y^{a}\left(F_{t}\right) N_{t}^{a}\right]^{\left(1-\epsilon^{a}\right)} .
$$

We also assume that fishing mortality costs are linear. This results from the assumption of closely homogenous fleets, which enables a linear relationship to be established (the catchability coefficient) between fishing days and fishing mortality. This is the most neutral assumption in regard to the assessment of the advantages of pulse fishing over stationary solutions. However, other cost configurations are also possible.

For instance it is well known that if fisheries showed increasing yields then costs would not be convex and the benefits from pulse fishing would be greater. Hake as a species does not appear suitable for school fishing along the lines of North Sea Herring.

However it is possible to assume that yields are decreasing, and that fishing costs are convex. For example van Oostenbrugge et al. (2008) show that when the number of days on which fleets may fish is limited, as is the case here, a more than proportional reduction in days is required to reduce fishing mortality, i.e. fishing mortality costs are convex.

What would be the implications for our model of abandoning the assumption of constant fishing mortality unit costs and prices? Under this new assumption the analytical solution could be characterized and the numerical solution found. Figure 4 shows the results of seeking the numerical solution using control vector parameterization if the following is used as the objective function

$$
\sum_{a=1}^{A}\left[\bar{p}^{a} y^{a}\left(F_{t}\right) N_{t}^{a}\right]^{\left(1-\epsilon^{a}\right)}-c F^{\alpha}
$$

[Insert Figure 4]

When $\epsilon=0$, the solution is similar to that for constant prices. If $\epsilon>0$, the price function introduces a mechanism that reduces the advantages of pulse fishing solutions: the more sensitive prices are to variations in catches, the more desirable stationary solutions become. Cost convexity also has a considerable impact. When $\alpha=1.5$, the stationary solution is optimal even with constant prices.

Concave and convex costs can be considered as reduced forms of more complex relationships that can be incorporated into the model. For instance Da Rocha, Cerviño and Gutiérrez (2010) show that it is possible to introduce fleet dynamics into an age-structured model, with forwardlooking firms that take decisions discounting the sum of future profits. Another possible extension of the model would be to consider that the catchability coefficient is not constant but dependent on time, horsepower and tonnage (see Da Rocha and Gutiérrez, 2011). Of course, these changes 
might influence the results, and our guess is that in a richer environment, periodic solutions would prove inferior to stationary ones.

As mentioned in the Introduction, there are cases of fisheries which are exploited on a pulse basis. However, in general the fact that stocks are exploited jointly by several countries, the non malleable nature of capital and employment, the impossibility of storing catches and the possibility of losing market access all make it inadvisable to use pulse solutions that would entail the closure of fisheries for some seasons. In other words stationary solutions are implemented because there are numerous effects not considered explicitly in the model that make pulse fishing inadvisable.

This study should be seen as measuring the institutional constraints faced by regulators. A comparison of the stationary and pulse solutions reveals a shadow price of all the implicit constraints not included in the model (non linear prices, convex costs, fleet dynamics, effort indices, etc). The numerical simulation run shows that when all these effects are ignored the stationary solution gives results only $2 \%$ below those of the pulse solution. This gives a measure in terms of discounted present value of all the factors not included in the model. If regulators, resorting to their experience and expertise, consider that reducing the sum total of discounted benefits by $2 \%$ is a low price to pay for keeping the fleet at work continuously, then our simulations show that the stationary solution is optimal.

\section{Acknowledgements}

This paper has benefited from comments and suggestions of the Editor, Dr Kenneth Rose and two anonymous referees. We are especially grateful to Olli Tahvonen, Anders Skonhoft and seminar participants at the First Age-structured Models in Fishery Economics and Bioeconomic Modeling Workshop, held in Trondheim, Norway, 12-13th of August 2009 and the participants in the Lisbon and Brussels 2007 North Hake Working Group Meetings. Financial aid from the European Commission (MYFISH, FP7-KBBE-2011-5), the Spanish Ministry of Science and Innovation (ECO2009-14697-C02-01 and 02) and the Xunta de Galicia (Anxeles Alvariño programme) is gratefully acknowledged. The first draft of the paper was written while Jose Maria Da Rocha was visiting Institut d'Anàlisi Econòmica-CSIC. He gratefully acknowledges its hospitality.

\section{References}

Baranov, F.I., 1918. On the question of the biological basis of fisheries . Institute for Scientific Ichthyological Investigations, Proceedings 1(1), 81-128.

Beverton, R.J.H., Holt, S.J., 1957. On the Dynamics of Exploited Fish Populations. Fish. Invest., II, 19. Republished by Chapman and Hall, 1993, London. 
Bjørndal, T., Brasão, A., 2006. The East Atlantic Bluefin Tuna Fisheries: Stock Collapse or Recovery? Marin. Resour. Econ. 21, 193:210.

Bjørndal, T., Gordon D., Kaitala, V., Lindroos, M., 2004a. International Management Strategies for a Straddling Fish Stock: A Bio-Economic Simulation Model of the Norwegian SpringSpawning Herring Fishery. Environ. Resour. Econ. 29, 435:457.

Bjørndal, T., Ussif, A., Sumaila, R., 2004b. A bioeconomic analysis of the Norwegian spring spawning herring (NSSH) stock. Marin. Resour. Econ. 19, 353:365.

Black, R., 2007. Catch cuts 'bring bigger profits". In: BBC News. Available at: http://news.bbc.co.uk/2 /hi/science/nature/7127761.stm.

Botsford, L.W., Quinn, J.F., Wing, S.R., Britmacher, J.G., 1993. Rotating spatial harvest of a benthic invertebrate, the red sea urchin, Strongylocentrotus franciscanus. In: Proceedings of the International Symposium on Management Strategies for Exploited Fish Populations. Alaska Sea Grant College Program AK-93-02, pp. 409-428.

Caddy, J.F., 1993. Background concepts for a rotating harvesting strategy with particular reference to the Mediterranean Red Coral, Corallium rubrum. Mar. Fish. Rev. 55, 10-18.

Caddy, J.F., Mahon, R., 1995. Reference Points for Fisheries Management. FAO Fish. Tech. Pap., 347.

Clark, C.W., 1976. Mathematical Bioeconomics. John Wiley, New York.

Cinner, J., Marnane. M.J., McClanahan, T.R., Almany, G.R., 2006. Periodic Closures as Adaptive Coral Reef Management in the Indo-Pacific. Ecol. Soc. 11, 31.

Da Rocha, J. M., Gutiérrez, M. J., Cerviño, S., 2010. Reference points as the steady-state solution for mixed fisheries management with bio-economic age-structured models. Mimeo.

Da Rocha, J. M., Cerviño, S., Gutiérrez, M. J., 2010. An endogenous bioeconomic optimization algorithm to evaluate recovery plans: an application to southern hake. ICES J. Mar. Sci., 67:19571962.

Da Rocha, J. M., Gutiérrez, M. J., 2011. Lessons from the long-term management plan for northern hake: Could the economic assessment have accepted it?. ICES J. Mar. Sci., doi:10.1093/icesjms/fsr105.

De la Maza, M., Yuret, D. ,1994. Dynamic hill climbing. AI Expert, 9(3): 26-31.

Dichmont, C. M., Pascoe, S., Kompas, T., Punt, A. E., Deng, R., 2010. On implementing maximum economic yield in commercial fisheries. PNAS 107, 16-21.

Commission Regulation (EC) No 1162/2001 of 14 June 2001 Establishing Measures for the Recovery of the Stock of Hake in ICES sub-areas III, IV, V, VI and VII and ICES Divisions VIII $\mathrm{a}, \mathrm{b}, \mathrm{d}$, e and Associated Conditions for the Control of Activities of Fishing Vessels Commission Regulation (EC) No 2602/2001 of 27 December 2001 Establishing Additional Tech- 
nical Measures for the Recovery of the Stock of Hake in ICES subareas III, IV, V, VI and VII and ICES Divisions VIIIa,b,d,e.

Commission Regulation (EC) No 492/2002 of 19 March 2002 Derogating from Regulation (EC) No 562/2000 Laying down Detailed Rules for the Application of Council Regulation (EC) No 1254/1999 as Regards the Buying-in of Beef and Amending Regulation (EEC) No 1627/89 on the Buying-in of Beef by Invitation to Tender

Council Regulation (EC) No 811/2004 of 21 April 2004 Establishing measures for the recovery of the Northern Hake Stock.

Egea, J.A., Balsa-Canto, E., García, M.S.G., Banga, J.R., 2009. Dynamic optimization of nonlinear processes with an enhanced scatter search method. Ind. Eng. Chem. Res 48(9), 43884401.

Grafton, R. Q., Kirkley, J., Kompas, T., Squires, D., 2006. Economics for fisheries management. Ashgat, London.

Grafton, R. Q., Kompas, T., Chu, L., Che, N., 2010. Maximum economic yield. Aust. J. Agric. Resour. Econ. 54, 273-280.

Grafton, R. Q., Kompas, T. and Hilborn, R.W., 2007. Economics of overexploitation revisited. Science, 318:1601.

Graham, T.R., 2001. Advantages of pulse fishing in live product fisheries. Live Reef Fish Inf. Bull. 9, 5-10.

Gröger, J. P., Rountree, R. A., Missong, M., and Rätz, H. J., 2007. A stock rebuilding algorithm featuring risk assessment and an optimization strategy of single or multispecies fisheries. ICES J. Mar. Sci. 64, 1101-1115.

Hannesson, R., 1975. Fishery dynamics: a North Atlantic cod fishery. Can. J. Econ. 8, 151-173.

Hart, D.R. (2003). Yield-and biomass-per-recruit analysis for rotational fisheries, with an application to the Atlantic sea scallop (Placopecten magellanicus). Fish. B.-NOAA, 101, 44-57.

Hart, D.R., Rago, P.J., (2006). Long-term dynamics of U.S. Atlantic sea scallop Placopecten magellanicus populations. N. Am. J. Fish. Manage. 26, 490-501.

Horwood, J.W., 1987. A Calculation of Optimal Fishing Mortalities. ICES J. Mar. Sci. 43, 199-208.

Horwood, J.W., Whittle, P., 1986. The optimal harvest from a multicohort stock. IMA J. Math. Appl. Med. Biol. 3, 143-155.

ICES (2007). Report of the Working Group on the Assessment of Southern Shelf Stocks of Hake, Monk and Megrim (WGHMM), 8-17 May 2007, Vigo, Spain. ICES CM 2007\ACFM:21, 700 pp. 
ICES, 2009. Report of the Working Group on the Assessment of Southern Shelf Stocks of Hake, Monk and Megrim (WGHMM), 5-11 May 2009, Copenhagen, Denmark. ICES CM 2009\ACOM:08, $537 \mathrm{pp}$.

Kompas, T., Dichmont, C. M., Punt, A. E., Dent, A., Che, T. N., Bishop, J., Gooday, P., Ye, Y., Zhou, S., 2010, Maximizing profits and conserving stocks in the Australian Northern Prawn Fishery. Aust. J. Agric. Resour. Econ. 54, 281-299.

Kulmala, S., Laukkanen, M., Michielsens, C., 2008. Reconciling economic and biological modeling of migratory fish stocks: optimal management of the atlantic salmon fishery in the Baltic Sea. Ecol. Econ. 64, 716-728.

Laguna, M. Martí, R., 2003. Scatter Search: Methodology and Implementations in C. Kluwer Academic Publishers: Norwell, MA.

Lassen, H., Medley, P., 2000. Virtual Population Analysis. A Practical Manual for Stock Assessment. FAO Fish. Tech. Pap., 400.

Mayne, D.Q., Rawlings, J.B, Rao, C.V. and J.O. Scokaert, 2000. Constrained Model Predictive Control: Optimality and Stability. Automatica. 36(6), 789-814.

McCallum, H.I., 1988. Pulse fishing may be superior to selective fishing. Math. Biosci. 89, $177-181$.

McKendrick, A.G., 1926. Applications of mathematics to medical problems. Proceedings of the Edinburgh Mathematical Society 44, 98-130.

Shepherd, J.G., 1982. A versatile new stock-recruitment relationship for fisheries, and the construction of sustainable yield curves. ICES J. Mar. Sci. 40(1), 67-75.

Spulber, D.F., 1983. Pulse-fishing and stochastic equilibrium in the multicohort fishery. J. Econ. Dyn. Control. 6, 309-332.

Scientific, Technical and Economic Committee for Fisheries (STECF). 2008a. Report of the sub-group on balance between resources and their exploitation (SGBRE). Northern hake long-term management plans (SGRE-07-03). (eds. Jardim E \& Hölker, F). 2008. Publication Office of the European Union, Luxemburg, ISBN 978-92-79-11044-3, JRC49104, 133pp.

Scientific, Technical and Economic Committee for Fisheries (STECF). 2008b. Report of the sub-group on balance between resources and their exploitation (SGBRE). Northern hake long-term management plans (SGRE-07-05). (eds. Van Hoof L \& Hölker, F). 2008. Publication Office of the European Union, Luxemburg, ISBN 978-92-79-11044-6, JRC49103, 106pp.

Storn, R., Price, K., 1997. Differential evolution. A simple and efficient heuristic for global optimization over continuous spaces. J. glob. optim. 11, 341-359.

Tahvonen, O., 2009. Economics of Harvesting Age-Structured Fish Populations . J. Environ. 
Econ. Manage. 58, 281-299.

Vassiliadis, V.S., 1993. Computational Solution of Dynamic Optimization Problems with General Differential-Algebraic Constraints. PhD Thesis. Imperial College. London.

Vassiliadis, V.S., Pantelides, C.C., Sargent, R.W.H., 1994. Solution of a class of multistage dynamic optimization problems. 1. Problems without path constraints. Ind. Eng. Chem. Res. 33(9), 2111-2122.

Von Foerster, H., (1959. Some remarks on changing populations. In The Kinetics of Cell Prolifeeration, 382-407.

Van Oostenbrugge, J.A.E., Powell, J.P., Smit. J.P.G., Poos, J.J., Kraak, S.B.M. and Buisman, F.C. (2008). Linking catchability and fisher behaviour under effort management. Aquatic Living Resources, 21, 265-273. 
Table 1: Age Structure and the Intertemporal Maximization Problem

\begin{tabular}{|c|c|c|c|c|c|c|c|c|}
\hline & \multicolumn{8}{|c|}{ Periods } \\
\hline Ages & $\mathrm{t}$ & $\mathrm{t}+1$ & $\mathrm{t}+2$ & $\ldots .$. & $\mathrm{t}+\mathrm{A}-2$ & $\mathrm{t}+\mathrm{A}-1$ & $t+A$ & $\mathrm{t}+\mathrm{A}+1$ \\
\hline$a=1$ & $N_{t}^{1}$ & & $N_{t+2}^{1}$ & $\ldots$. & & & & \\
\hline$a=2$ & $N_{t}^{2}$ & $N_{t+1}^{2}$ & & $\ldots$. & $N_{t+A-2}^{2}$ & & & \\
\hline$\ldots$ & $\ldots$ & $\ldots$ & $\ldots$ & $\ldots$. & & $\ldots$ & $\ldots$ & $\ldots$ \\
\hline$a=A-1$ & $N_{t}^{A-1}$ & $N_{t+1}^{A-1}$ & $N_{t+2}^{A-1}$ & $\ldots$. & $N_{t+A-2}^{A-1}$ & & $N_{t+A}^{A-1}$ & \\
\hline $\mathrm{a}=\mathrm{A}$ & $N_{t}^{A}$ & $N_{t+1}^{A}$ & $N_{t+2}^{A}$ & $\ldots$. & $N_{t+A-2}^{A}$ & $N_{t+A-1}^{A}$ & & $N_{t+A+1}^{A}$ \\
\hline
\end{tabular}

An increase in $F_{t}$ leads to 1 ) an increase in current fishery profits because affects to the captures in period $t$ (column $\mathrm{t}), 2)$ a decrease in future profits because reduce the future stock of current living cohorts (lower triangle matrix) and 3) a decrease in future profits because future stock recruitments is reduced (row $a=1$ and upper triangle matrix). 
Table 2: North Stock of hake. Characteristics of the Spanish Fleet (2004)

\begin{tabular}{|c|c|c|c|c|}
\hline Segment Fleet & Length Class & Number of vessels & Total employment & Gross Value Added (m€) \\
\hline Demersal Trawlers & $24-40 \mathrm{~m}$ & 93 & 1,023 & 56.8 \\
\hline Pair Demersal Trawlers & $24-40 \mathrm{~m}$ & 20 & 239 & 9.6 \\
\hline Longliners & $24-40 \mathrm{~m}$ & 84 & 1,176 & 59.8 \\
\hline Total & & 197 & 2,438 & 126.2 \\
\hline
\end{tabular}

Source: STECF, 2008b. Tables 6.1.5, 6.1.6, 6.1.8 y 6.1.9 
Table 3: North Stock of hake. Characteristics of the French Fleet (2006)

\begin{tabular}{|llrrr|}
\hline Segment Fleet & Length Class & Number of vessels & Total employment & Gross Value Added $(\mathrm{m} €)$ \\
\hline \hline DTS-Targeted Nephrops & $12-24 \mathrm{~m}$ & 204 & 759 & 45.4 \\
DTS-Targeted Fish & $12-24 \mathrm{~m}$ & 106 & 490 & 35.9 \\
DTS & $24-40 \mathrm{~m}$ & 55 & 389 & 28.9 \\
Hook & $24-40 \mathrm{~m}$ & 5 & 62 & 2.3 \\
Netters & $12-24 \mathrm{~m}$ & 60 & 351 & 22.2 \\
Netters & $24-40 \mathrm{~m}$ & 18 & 223 & 11.3 \\
Others & - & 210 & 803 & - \\
\hline Total & & 658 & 3,077 & - \\
\hline
\end{tabular}

DTS= Demersal trawls seiners Source: STECF, 2008b. Tables 6.2.5, 6.2.8-6.2.13

Source: STECF, 2008b. Tables 6.2.5, 6.2.8-6.2.13 
Table 4: Northern Stock of hake. Parameters by age

\begin{tabular}{|c|c|c|c|c|c|c|c|c|c|c|c|}
\hline & \multicolumn{11}{|c|}{ Initial conditions } \\
\hline & Age 0 & Age 1 & Age 2 & Age 3 & Age 4 & Age 5 & Age 6 & Age 7 & Age 8 & Age 9 & Age 10 \\
\hline \multirow[t]{3}{*}{$N^{a}$} & 186,213 & 152,458 & 123,457 & 100,213 & 67,409 & 35,551 & 19,674 & 10,206 & 9,147 & 4,078 & 1,819 \\
\hline & \multicolumn{11}{|c|}{ Population dynamics } \\
\hline & Age 0 & Age 1 & Age 2 & Age 3 & Age 4 & Age 5 & Age 6 & Age 7 & Age 8 & Age 9 & Age 10 \\
\hline$p^{a}$ & 0.00 & 0.06 & 0.54 & 1.15 & 1.03 & 1.52 & 2.09 & 2.43 & 2.43 & 2.43 & 2.43 \\
\hline$\omega^{a}$ & 0.06 & 0.13 & 0.22 & 0.34 & 0.60 & 0.98 & 1.44 & 1.83 & 2.68 & 2.68 & 2.68 \\
\hline \multirow[t]{3}{*}{$\mu^{a}$} & 0.00 & 0.00 & 0.00 & 0.23 & 0.60 & 0.90 & 1.00 & 1.00 & 1.00 & 1.00 & 1.00 \\
\hline & \multicolumn{11}{|c|}{ Prices } \\
\hline & Age 0 & Age 1 & Age 2 & Age 3 & Age 4 & Age 5 & Age 6 & Age 7 & Age 8 & Age 9 & Age 10 \\
\hline$p r^{a}$ & 2.36 & 2.93 & 3.42 & 3.85 & 4.55 & 5.22 & 5.81 & 6.22 & 6.92 & 6.92 & 6.92 \\
\hline
\end{tabular}

Source: Meeting on Northern Hake Long-Term Management Plans (STECF/SGBRE-07-03) and ICES (2007). $N^{a}$ is the number of fishes of age $a$ in thousand; $p^{a}$ is the selectivity parameter; $\omega^{a}$ is the weigth of age $a$ in $\mathrm{kg} ; \mu^{a}$ is the maturity fraction of age $a ; p r^{a}$ is the prices of age $a$ in Euros per kg. 


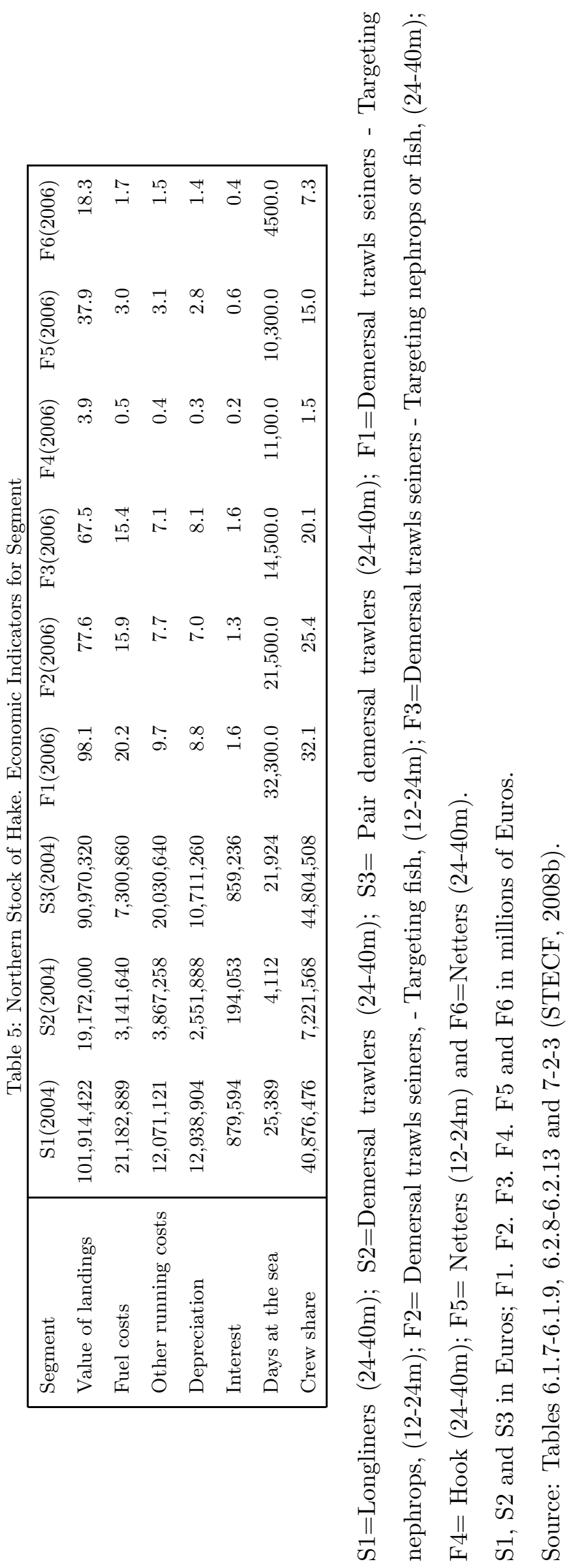




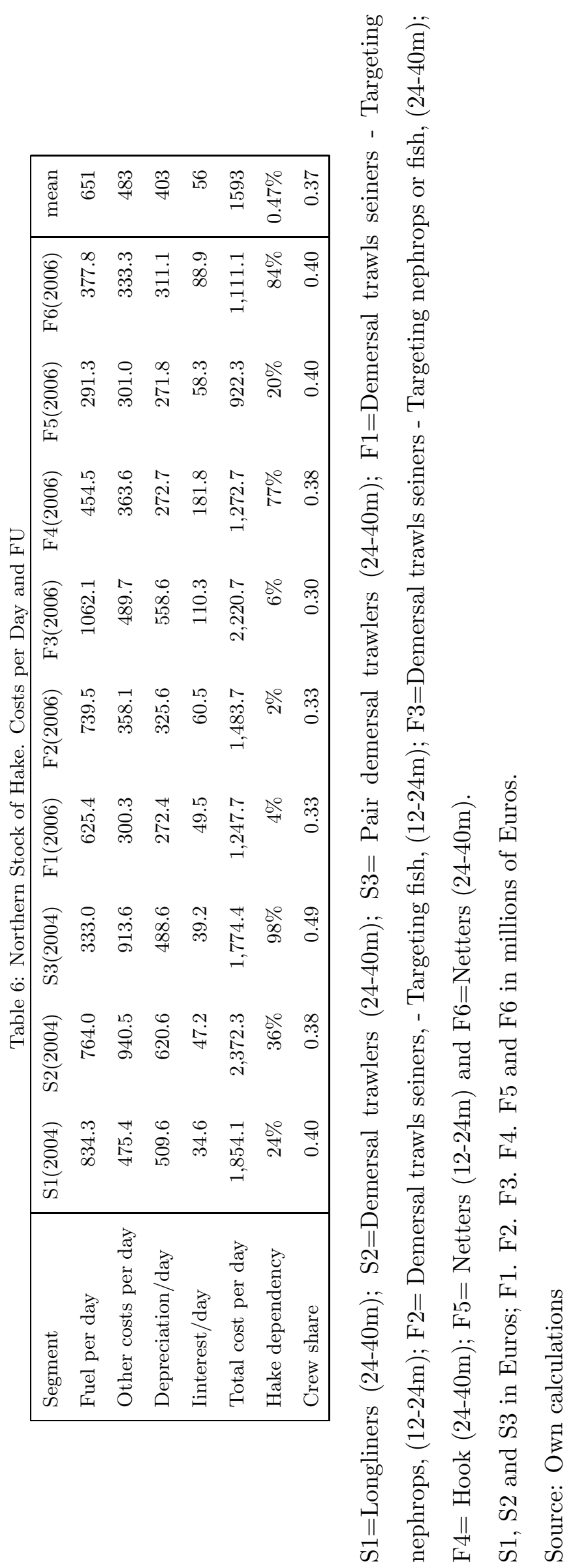


Table 7: Comparison of the three scenarios: smooth driven to the reference point $\left(F_{m s y}\right)$, stationary solution $\left(F_{s s}\right)$ and global optimal solution $\left(F_{\text {periodic }}\right)$. Positive costs.

\begin{tabular}{|r|ccc|cc|}
\hline & \multicolumn{3}{|c|}{ Long Run Values } & \multicolumn{2}{c|}{ Net Present Profits } \\
& $F$ & SSB $(\mathrm{kTn})$ & Yield $(\mathrm{kTn})$ & Euros & \% over Scenario 1 \\
\hline Scenario 1: $F_{\text {msy }}$ & 0.172 & $1.9807 e+005$ & $3.395 e+005$ & $3.5752 e+006$ & 100.00 \\
Scenario 2: $F_{\text {ss }}$ & 0.119 & $2.5414 e+005$ & $3.314 e+005$ & $4.2736 e+006$ & 119.53 \\
Scenario 3: $F_{\text {periodic }}$ & & & $4.3562 e+006$ & 121.85 \\
year 1 & 0 & $1.6719 \mathrm{e}+005$ & 0 & & \\
year 2 & 0 & $2.1240 \mathrm{e}+005$ & 0 & & \\
year 3 & 0 & $2.6985 \mathrm{e}+005$ & 0 & & \\
year 4 & 0.489 & $3.5476 e+005$ & $13.500 e+005$ & & \\
\hline
\end{tabular}

The net present value of the profits associated with each trajectory is calculated using $\beta=0.95 . F_{m s y}$ is simulated as the fishing rate that maximises the stationary yield. $F_{s s}$ is obtained using the algorithm proposed in Section 3.2. $F_{\text {periodic }}$ is obtained using the hybrid strategy. The efficiency analysis shows that this global method is more efficient than the diferential evolution and enhanced scatter search methods. 
Table 8: Comparison of the three scenarios: smooth driven to the reference point $\left(F_{m s y}\right)$, stationary solution $\left(F_{s s}\right)$ and global optimal solution $\left(F_{\text {periodic }}\right)$. Zero costs.

\begin{tabular}{|l|cc|}
\hline & \multicolumn{2}{|c|}{ Net Present Profits } \\
& Euros & $\%$ over Scenario 1 \\
\hline scenario 1: $F_{m s y}$ & $6.2946 e+006$ & 100.00 \\
scenario 2: $F_{\text {ss }}$ & $6.3363 e+006$ & 100.66 \\
scenario 3: $F_{\text {periodic }}$ & $6.3906 e+006$ & 101.53 \\
\hline
\end{tabular}

The net present value of the profits associated with each trajectory is calculated using $\beta=0.95 . F_{m s y}$ is simulated as the fishing rate that maximises the stationary yield. $F_{s s}$ is obtained using the algorithm proposed in Section 3.2. $F_{\text {periodic }}$ is obtained using the hybrid strategy global method. The efficiency analysis shows that this global method is more efficient than the differential evolution and enhanced scatter search methods. 


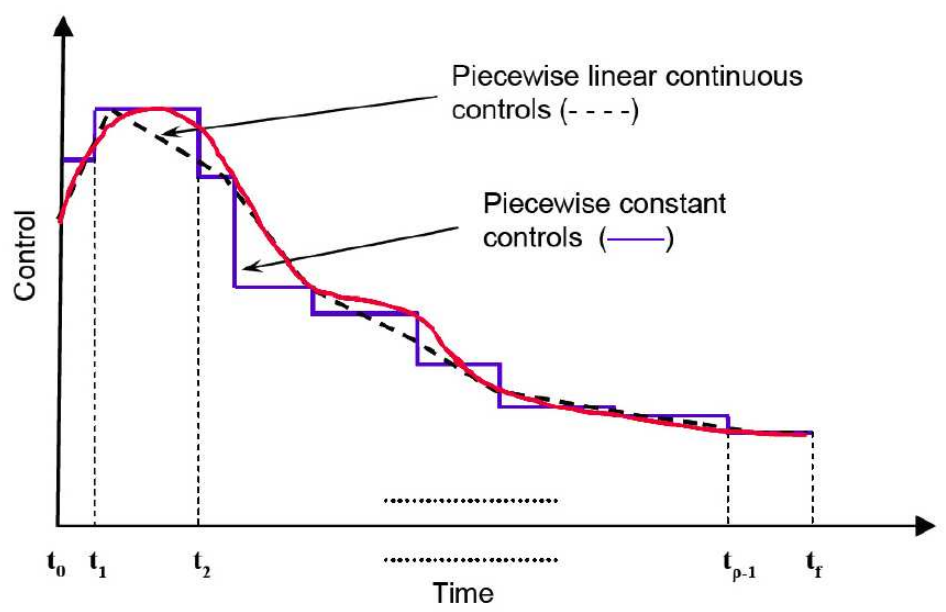

Figure 1: Control Vector Parameterization scheme. Controls are approximated in each interval using different base functions (steps and ramps in this example). 


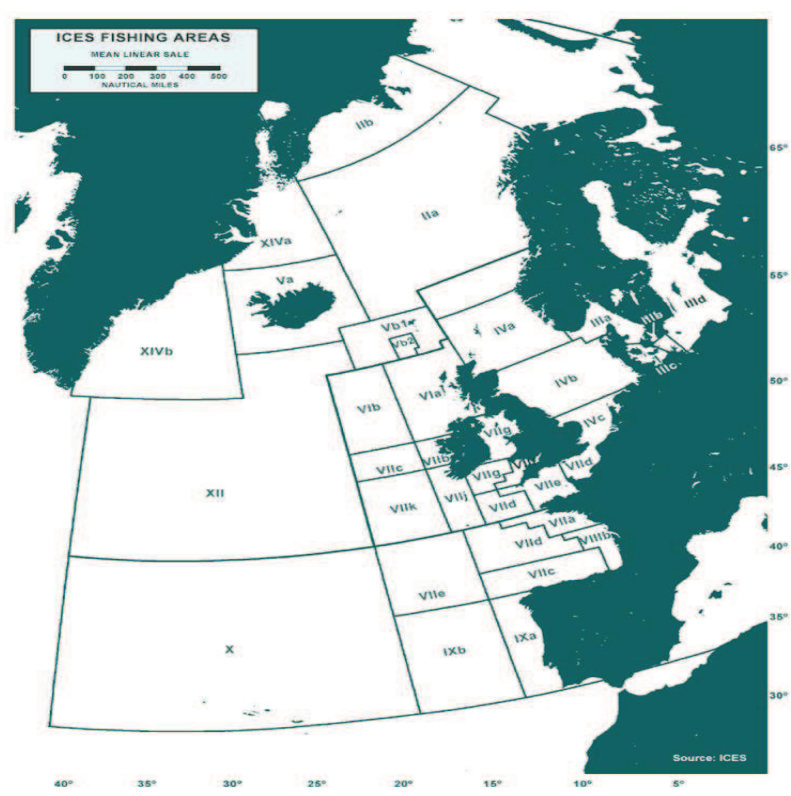

Figure 2: The North Stock of hake includes ICES subareas VII and VIII and also some fisheries in Subareas IV and VI. 

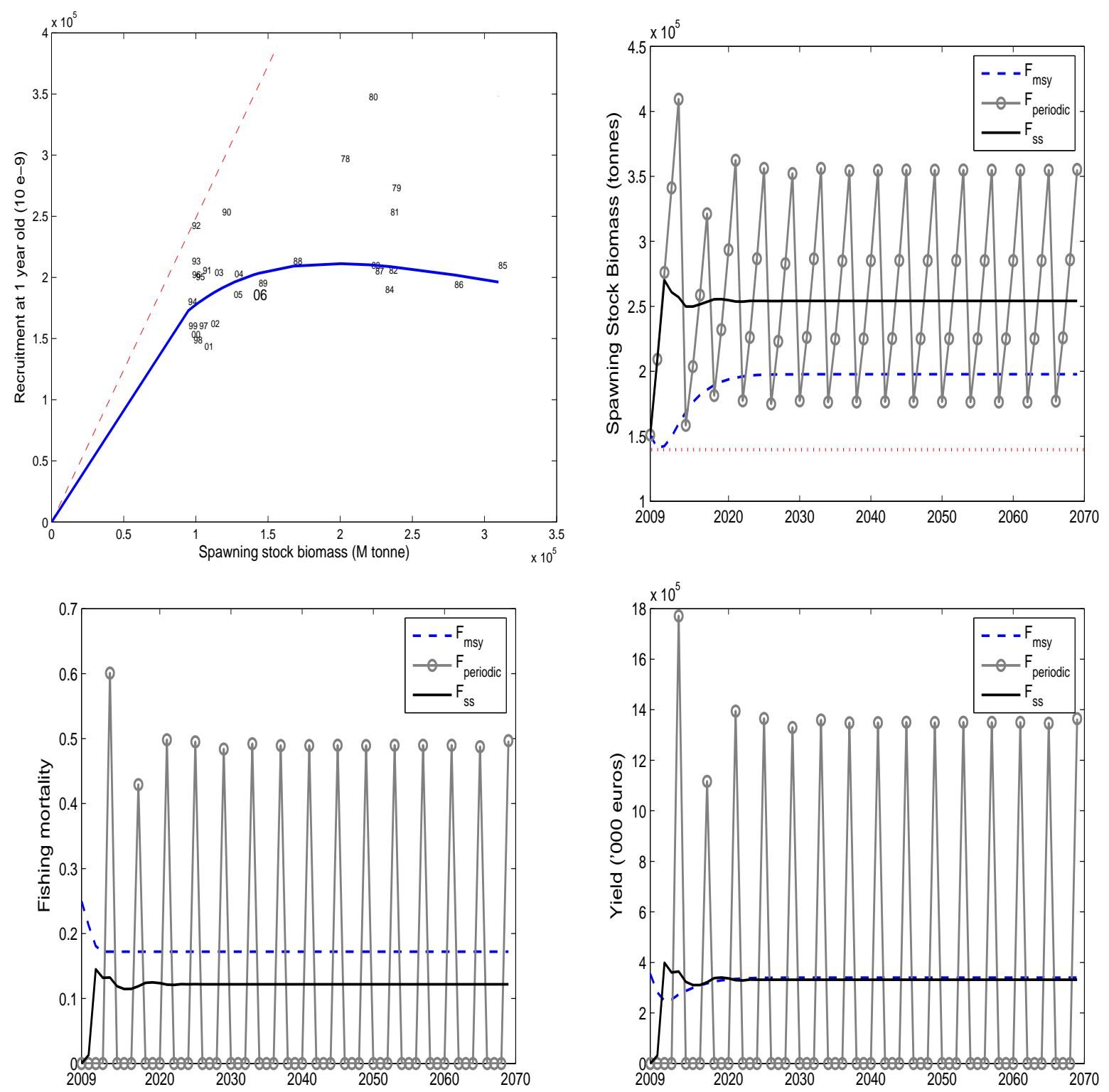

Figure 3: Trajectories under the three scenarios: optimal ( $\left.F_{\text {periodic }}\right)$ obtained using the hybrid strategy global method, the stationary solution $\left(F_{s s}\right)$ obtained using algorithm proposed in Section 3.2. and the smooth driven to the reference point $\left(F_{m s y}\right)$. Stock recruitment relationship (upper left panel). $S S B$ (upper right panel); fishing mortality (lower left panel) and yield (lower right panel). 

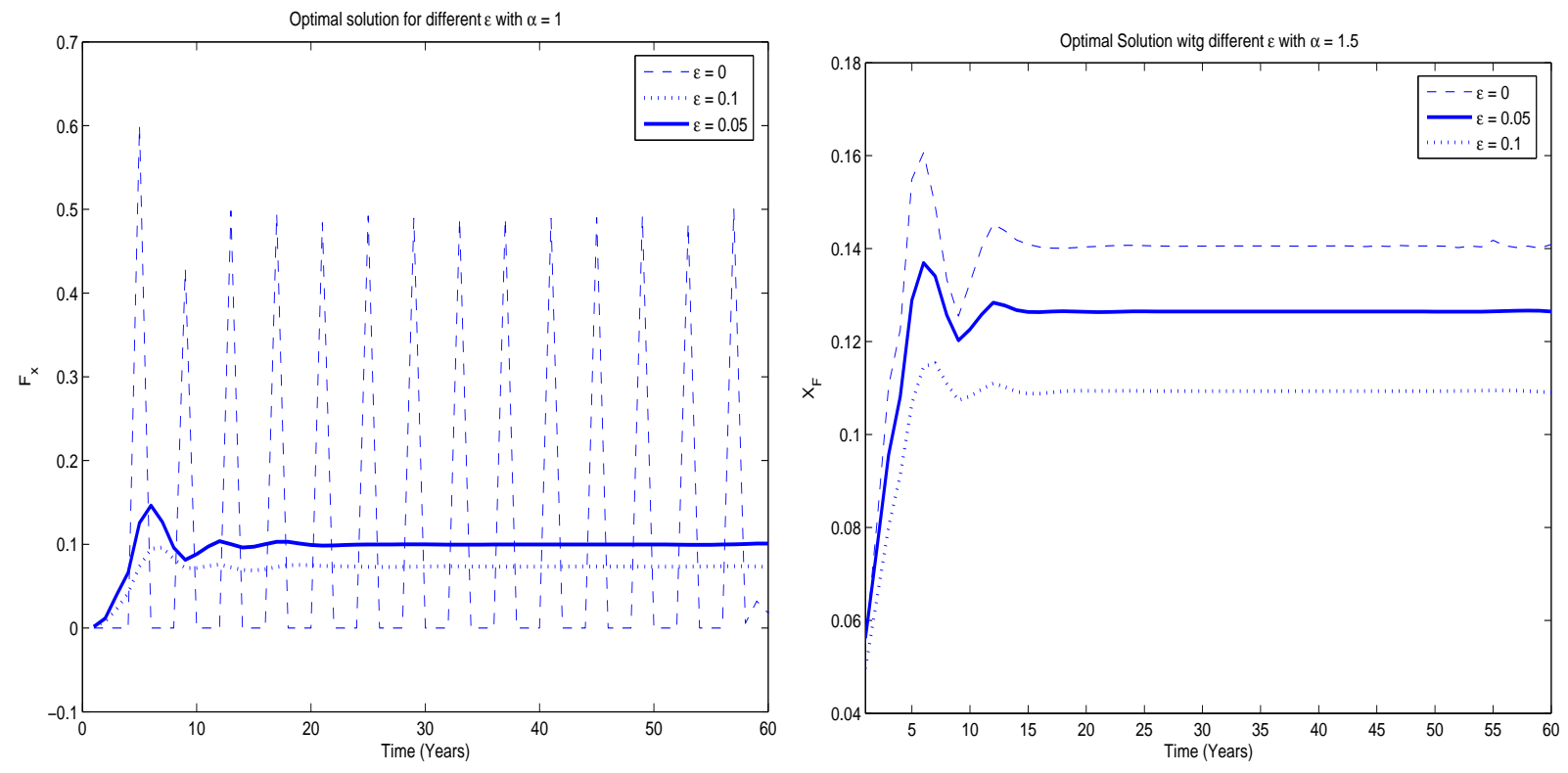

Figure 4: Simulating the optimal solution assuming that prices are isoelastic functions of quantities and costs are convex. High values of $\epsilon$ indicates that prices are more sensitive to changes in quantities. Values of $\alpha>1$ indicates that the cost function is convex. $\epsilon=0$ and $\alpha=1$ represents the case of constant prices and linear costs. 